\title{
Experimental investigation of desiccant dehumidification based thermoelectric air-conditioning system
}

DOI:10.36909/jer.13001

Anurag Maheswari*, Manoj Kumar Singh*, Yogesh K. Prajapati**, Niraj Kumar*, Vineet Singh*

*Department of Mechanical Engineering, FET, MJP Rohilkhand University, Bareilly, India.

** Department of Mechanical Engineering, NIT Uttrakhand, Srinagar (Garhwal) Uttarakhand, 246174, India.

*Email: anurag.maheswari@gmail.com; Corresponding Author.

\begin{abstract}
Vapor compression refrigeration system (VCRS) based conventional cooling systems run on the high amount of electricity and refrigerants responsible for greenhouse emissions. To save the environment and high-grade energy, traditional cooling systems should be replaced with some environment-friendly alternative. This paper proposed alternative eco-friendly airconditioning systems based on an amalgam of two different technologies, i.e., desiccant dehumidification and thermoelectric (TE) cooling. The proposed air-conditioning system has the following subprocess: dehumidification of moist air by the solid desiccant wheel, cooling of processed air by TE modules, and regeneration of desiccant wheel by an electric heater and waste heat from TE modules. The air conditioning system has been experimentally studied for cooling performance, cooling effect, and energy input. The maximum coefficient of performance of 0.865 can be achieved with the proposed system, and it can be used for cooling effects up to $1442.24 \mathrm{~W}$ to maintain the human comfort condition in the chamber i.e. approximately $22{ }^{\circ} \mathrm{C}$ and $\mathrm{RH} 50 \%$ defined by ASHRAE.
\end{abstract}

Key words: coefficient of performance; desiccant dehumidification; thermoelectric cooling 


\section{INTRODUCTION}

About $15 \%$ of worldwide electrical energy is used up by quite a lot of air conditioning and refrigeration devices, and $59 \%$ of the energy intake in commercial and domestic structures is assigned to air conditioning and water heating systems (Building Energy Data Book, 2011). The conventional air conditioning devices works on vapor compression refrigeration system (VCRS) are highly responsible for thermal pollution and waste of energy in the form of discharged heat of condensation in the environment. Some of the other disadvantages of (VCRS) i.e. first, they run by electricity produced by burning natural resources, which is responsible for greenhouse effect and pollution. Second, refrigerant used in VCRS if leaked can cause ozone layer depletion (Zhong et al., 2015). VCRS based cooling system should be replaced with some environment friendly alternative to save environment and high grade energy (Berardi et al., 2017).

Thermoelectric (TE) module can be used as thermoelectric cooler (TEC) (Xi et al., 2007) and as power generator (Luo et al., 2019). TEC have no moving part or working fluid as compared to traditional VCRS based systems therefore considered as pollution free cooling method and TE modules are extensively used in wide range of application in aerospace, cooling, military etc. due to its benefits like reliability, less weight and easy replicability (Sofrata H., 1984, Cheng et al., 2011, Wang, R.Z. \& Dai, Y.J. 2001). TEC systems can successfully use to reduce CPU temperature (Naphon P. \& Wiriyasart, S., 2009). with the advantage of noiseless and movement free operation, TEC systems have been used in car seats and small space cooling requirements in buildings (Choi et al., 2007 \& Gillott et al., 2010). The TE systems can divide in two sub-categories: TE integrated systems and TE nonintegrated systems (Zuazua-Ros et al., 2019). Photovoltaic (PV) cells can also integrated with TE systems where electricity produced by PV cell is used to run TE system for refrigeration and heating (Luo et al., 2019). Despite the rise in cooling capacity, COP of the thermoelectric significantly decreases by increase of input power. Use of more TE modules 
results in increase in COP but it also increases the cost (Tian et al., 2021).

As an approach towards environment friendly air conditioning systems, desiccant based air conditioning systems (DBACS) also attracted the attention of the researchers. A DBACS can be run by low grade heat energy which can easily harnessed from the sun and can save high grade electricity demand. DBACS have the potential to be used as air conditioning systems specially in humid climates (Kodama et al., 2001, Steven Brown, j. \& Domanski, P.A., 2014). Solid desiccant like silica gel, zeolite etc. are relatively easy to handle as compare to liquid desiccant (Al-Alili et al., 2015 \& Ge et al., 2009). A honeycomb wheel base packed with desiccant material is one of the important part of solid DBACS. The two main operation processes of system are adsorption (dehumidification) and desorption (regeneration). In first phase damped air get dehumidified when passed through the desiccant wheel rotating at low rpm and this dehumidified air is further need to be cooled by some other system before supplied to the room as its temperature rises due to adsorption heat. In second phase desiccant wheel is regenerated by passing the high temperature air which is usually exhausted outside (Li H. et al., 2013). A DBACS is simulated and experimented with an evaporator for outdoor conditions to analyse, inlet humidity ratio, regeneration temperature, COP, energy intake and energy saving rates are reported (Shahzad et al., 2018 \& Ying et al., 2015). Compared to direct and indirect evaporative cooling system, hybrid desiccant cooling system have significantly high COP for outdoor temperature greater than $40{ }^{\circ} \mathrm{C}$ (Lee et al., 2021).

The important Psychometric process of air conditioning device is cooling and dehumidification of moist air. Hence in the present work an amalgam of desiccant based dehumidification and thermoelectric cooling system is proposed as an eco-friendly alternative for conventional air conditioning devices works on VCRS. The system uses desiccant wheel for dehumidification for moist air, electric heater for regeneration of desiccant wheel and thermoelectric devices have been powered by solar panels for cooling of 
process air which is supplied to the room. Researchers has done a major amount of research to investigate DBACS and TEC systems separately but their amalgam is not being studied as per author knowledge.

\section{EXPERIMENTAL SETUP AND METHODOLOGY}

In the proposed research, an air-conditioned system with desiccant dehumidification and thermoelectric cooling (as shown in figure 1), is developed and studied. Experimental setup is consisting of four major parts i.e. solar power system, desiccant dehumidifier, TEC (Thermoelectric cooler) and the cooling chamber. A commercial desiccant dehumidifier having zeolite packed desiccant wheel is used with the dehumidification capacity of 8 litres/day and regeneration of the wheel is achieved by a small electric heater. Depending upon the atmospheric condition, dehumidifier controls and maintains the relative humidity of the cooling chamber at $50 \%$.

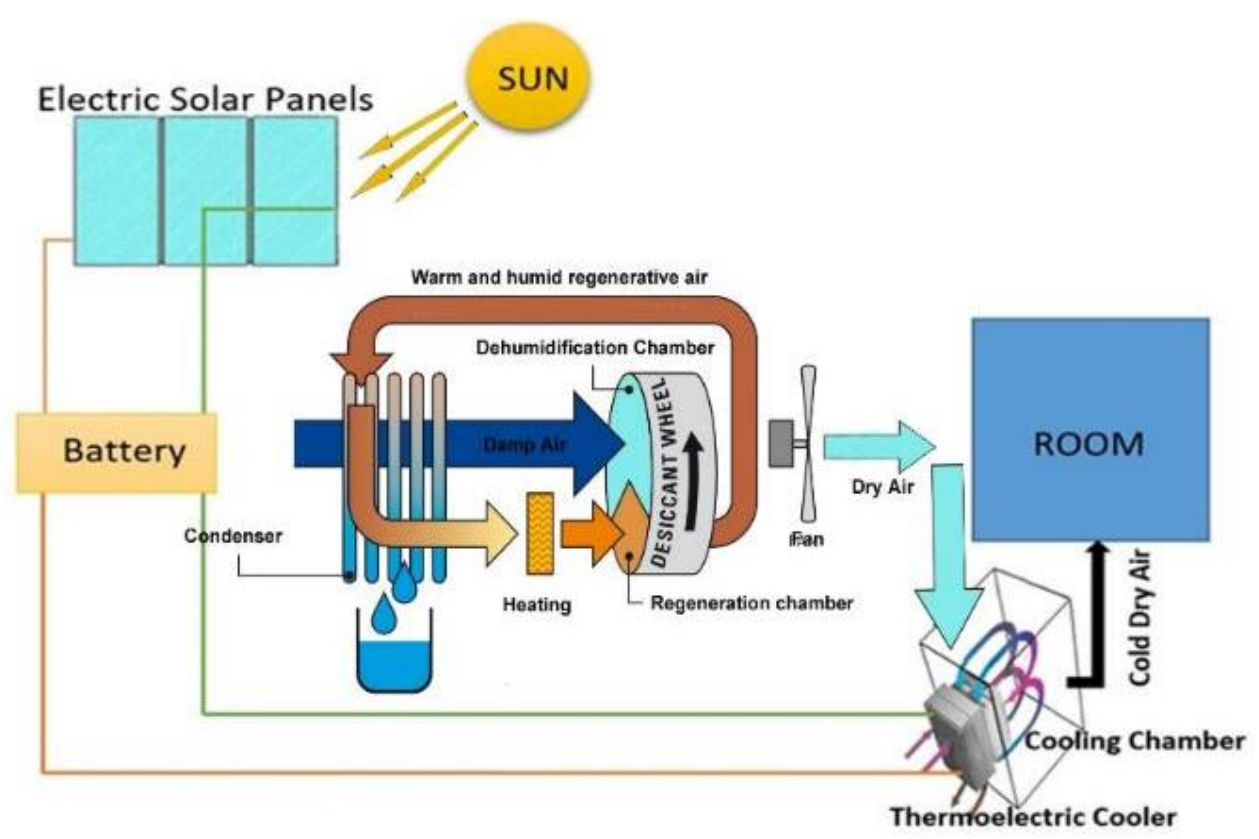

Figure 1. Schematic of air-conditioning system

A TEC is constructed with a frontal area of 1 sq. ft. (as shown in figure 2) using total $28 \mathrm{TE}$ module (TEC1-12706) arranged on four faces of the TEC. Hot side of the TE modules are connected with water cooled mini-channel heat sink and on the cold side, aluminium fins with 
an axial fan are used to ensure efficient cooling of process air entering to the room. The dehumidified air at the exit of dehumidifier is enters to the TEC, at the exit of TEC cold and dry air at required temperature and relative humidity is entered to the cooling chamber to provide the required comfort. Both the desiccant dehumidifier and TEC are powered by electricity produced by solar panels. The walls of cooling chamber are made up of wood with thermal insulation of thermocol, the overall dimension of the cooling chamber is $4 \times 2 \times 2 \mathrm{cu}$. $\mathrm{ft}$. The process start with the commercial desiccant wheel dehumidifier consist of desiccant wheel made up of Zeolite material, in first step the desiccant dehumidifier sucks the air from the cooling chamber and the desiccant wheel is used to absorb the moisture from the air and dehumidified it at required relative humidity (as shown in figure 2), then this process air is transferred to thermoelectric cooler where it is cooled to the comforting temperature. Finally, this cold and dry air is entered in the cooling space. In second chamber of desiccant wheel, a small electric heater is installed to regenerate the desiccant wheel.

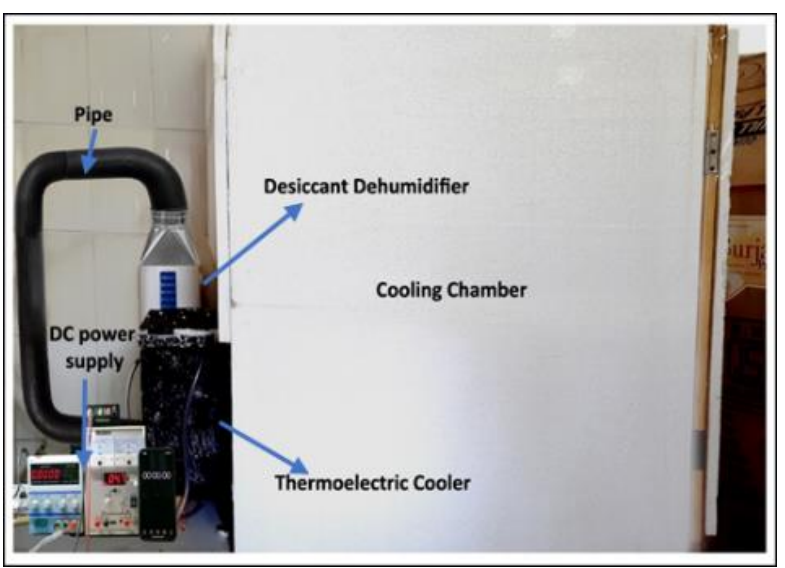

Figure 2. Experimental Setup of desiccant based TE cooled air-conditioning system

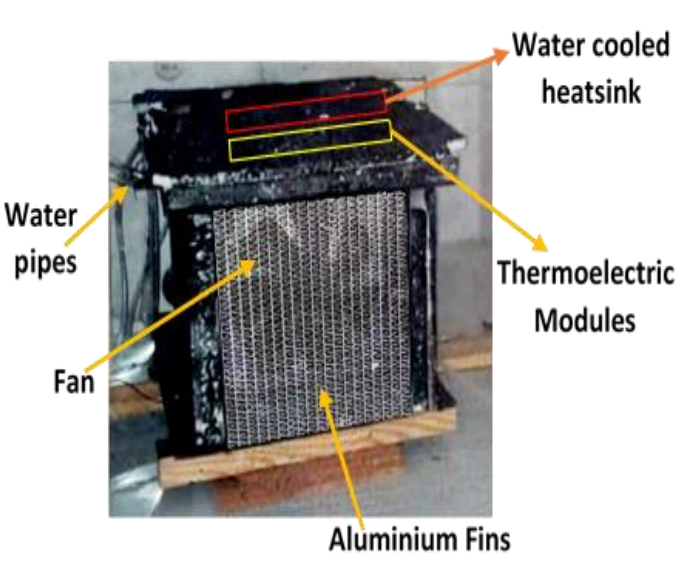

Figure 3. Thermoelectric cooler

\section{EXPERIMENTAL ANALYSIS}

The objective of this research is to determine the overall COP (Coefficient of performance) of the proposed system. For calculating the COP, the net cooling effect required and the total power consumed by the TEC is determined.

$$
C O P=\frac{Q_{T}}{W_{T E C}}
$$


In the above equation, $\mathrm{Q}_{\mathrm{T}}$ is the total cooling effect which means amount of heat needed to extract from the cooling chamber.

$$
Q_{T}=Q_{S}+Q_{L}
$$

$\mathrm{Q}_{\mathrm{S}}$ is the heat entering to the chamber after dehumidification and $\mathrm{Q}_{\mathrm{L}}$ is the heat entering to the chambers through the walls.

$\mathrm{W}_{\mathrm{TEC}}$ is the net power consumed by the TEC which can be determined by using following equation:

$$
W_{T E C}=n * V * I
$$

In the above equation $\mathrm{n}$ is the number of TE module used, $\mathrm{V}$ is the electric voltage and $\mathrm{I}$ is the current intensity.

\section{RESULTS \& DISCUSSION}

In the present work, amalgam of desiccant dehumidification and TE cooling is achieved and performance of the system is evaluated by considering two major factors COP and comfort condition inside the chamber i.e. $22{ }^{\circ} \mathrm{C}$ and $\mathrm{RH} 50 \%$ defied by ASHRAE. The experimental investigation is carried out for the months of May, June, July and August at Bareilly $\left(28.3670^{\circ} \mathrm{N}, 79.4304^{\circ} \mathrm{E}\right)$, India. By maintaining the comfort condition inside the chamber several parameters are studied.

Figure 4 depicts the variation of ambient temperature and dehumidified air entering to the TEC in the month May, June, July and August during the different time of the day (9:30 am to 5:30 pm). The temperature of process air at the Inlet to the TEC is higher than that of ambient because of the sensible heat added to it during the regeneration of the desiccant wheel. The maximum ambient temperature reported $38^{\circ} \mathrm{C}$ continuously for three hours in the month of May and minimum temperature recorded is $29^{\circ} \mathrm{C}$. 

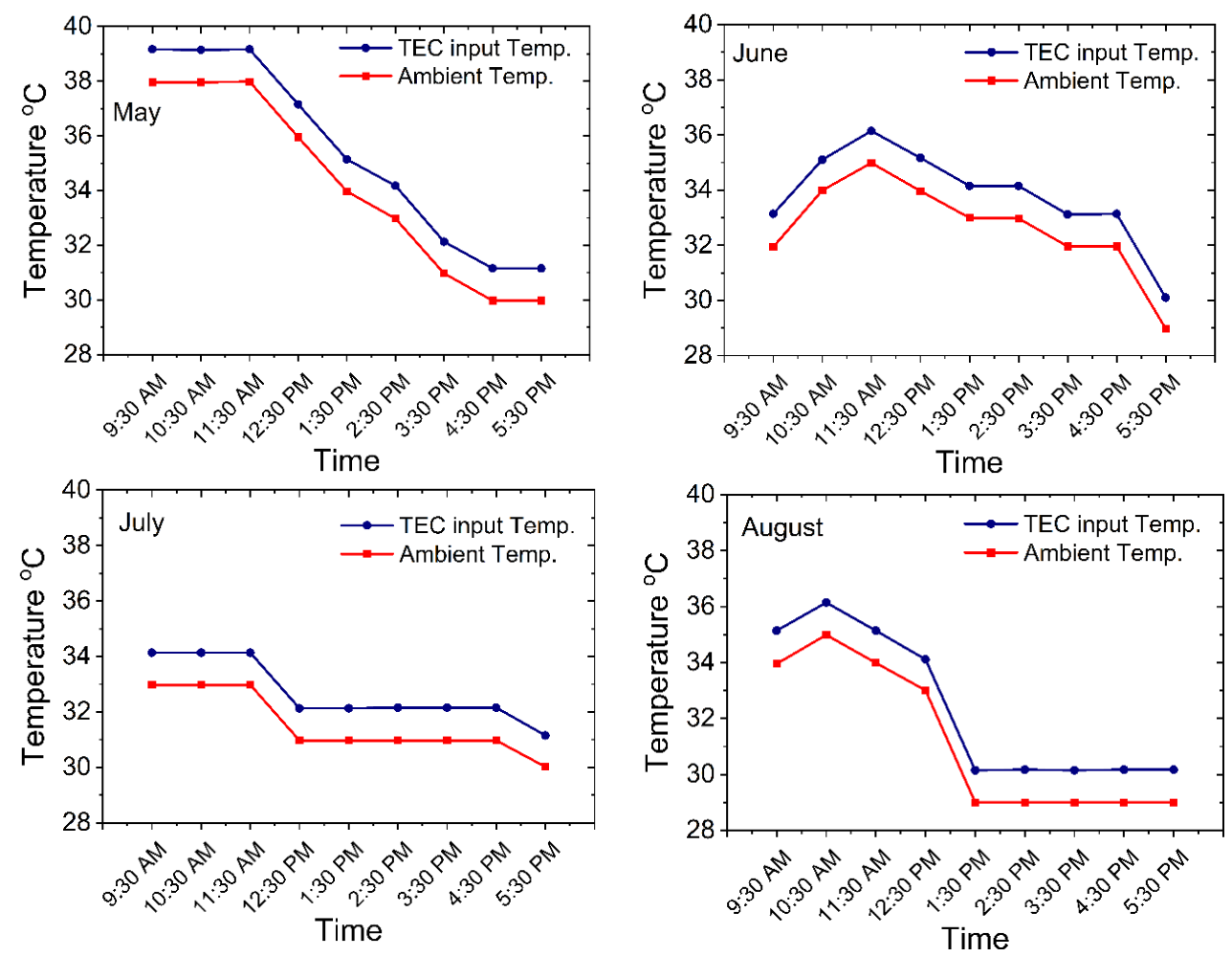

Figure 4. Temperature variation with time of ambient air and TEC inlet

Heat is to be removed from the cooling chamber in order to maintain its temperature in required comfort range. Sensible heat inside the cooling chamber increase the temperature air whereas latent heat is responsible for the moisture content of the space. As humidity level is already controlled by the desiccant dehumidifier so TEC is used only to extract the sensible heat from the chamber. Figure 5 shows the variation the cooling load requirement at the different time of the day of different months. The major portion to the total cooling load is contributed by the heat enter in the chamber through the process air after the dehumidification. The heat entering to the chamber through the room walls is comparatively less as the chamber is well insulated. The trends of total cooling load depict that higher the ambient temperature higher will be the cooling load inside the chamber. Maximum cooling load of $1442.24 \mathrm{~W}$ reported for the month of May and minimum cooling load is $579.12 \mathrm{~W}$. 

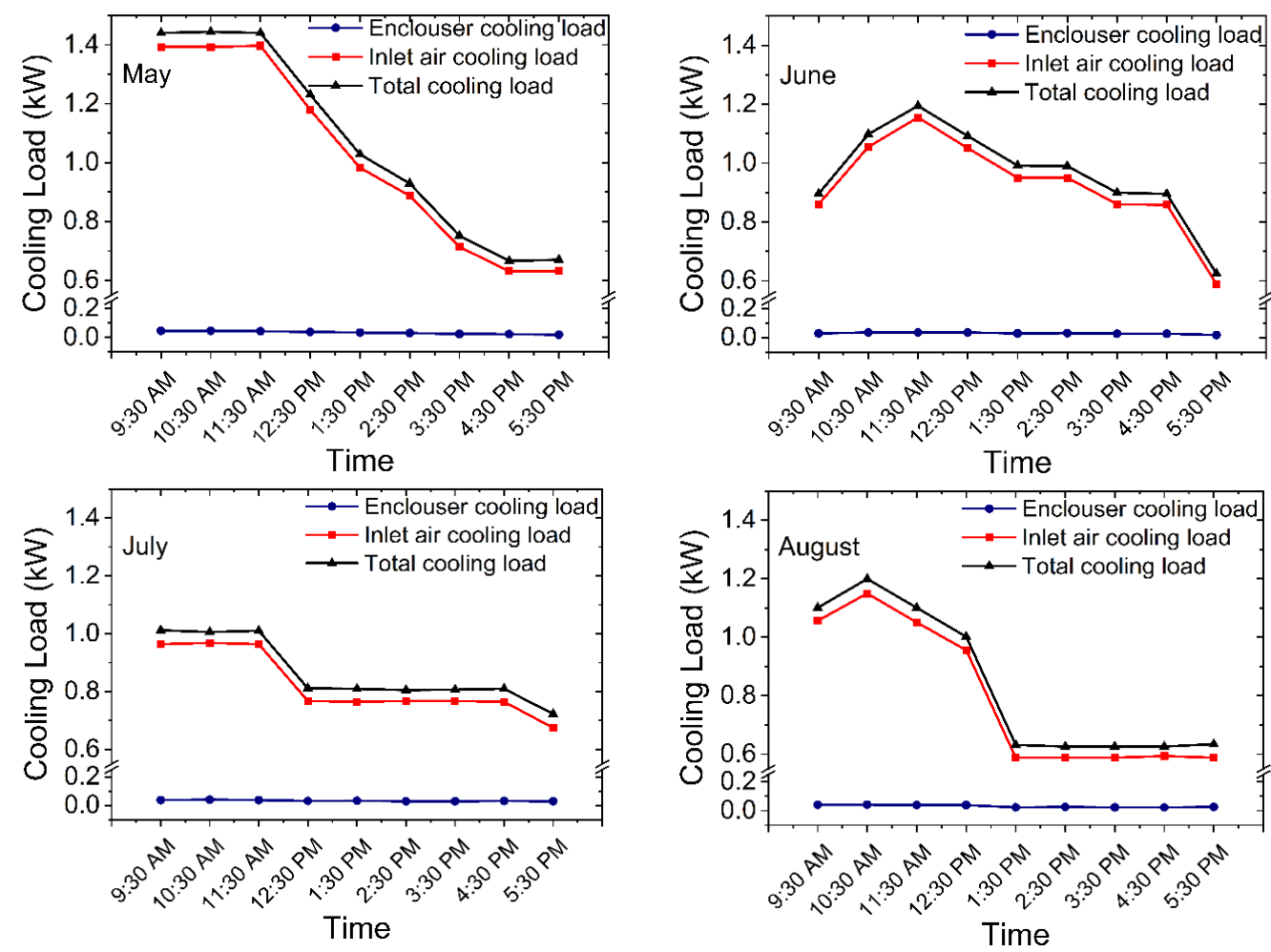

Figure 5. Cooling load variation of process air and enclosure with time

TEC modules use the Peltier effect to extract the heat from cooling side and transfer it to the hot side by the consumption of electrical energy based on the current intensity and electric voltage supplied. Figure 6 and 7 shows the variation of current intensity and electric voltage supplied respectively as the input to the TEC at different times of the day. It can be seen that the trends for both the plots are similar. When the ambient temperature is maximum, higher current intensity and electric voltage is required to run TEC in order to achieve the necessary cooling and with the decrease in temperature at different time of the day values of current intensity and voltage input decreases. In the month June the value of temperature at $10.30 \mathrm{am}$ is high as compare to 9.30 am but still the value of current intensity and electric voltage is $4 \mathrm{~A}$ and $10 \mathrm{~V}$ respectively depending on the performance curves of TEC1-12706 and limitation on the power supply. Same phenomenon can be noticed in trends at different time of day in all four months. 

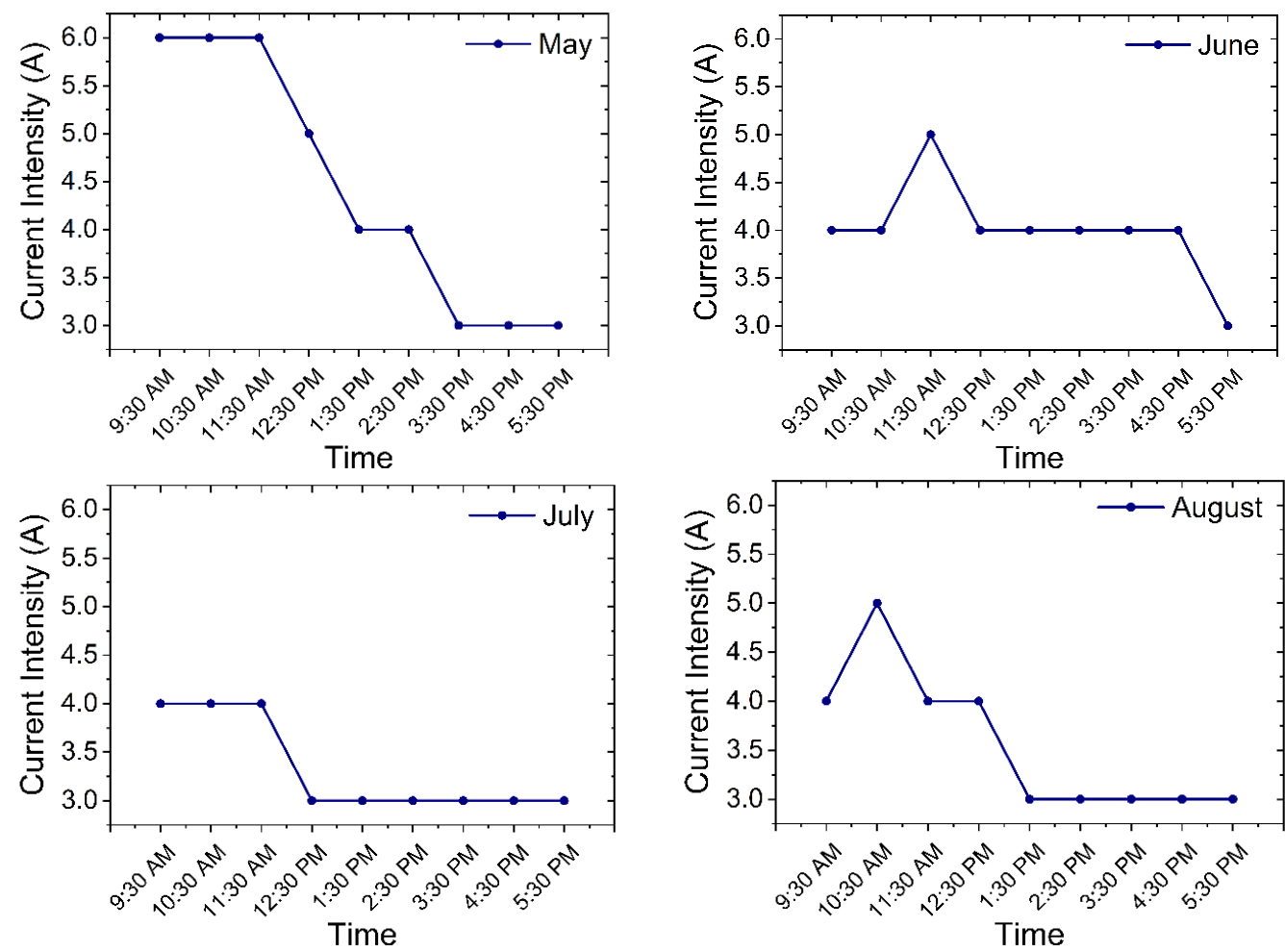

Figure 6. Current intensity variation with time for TE module
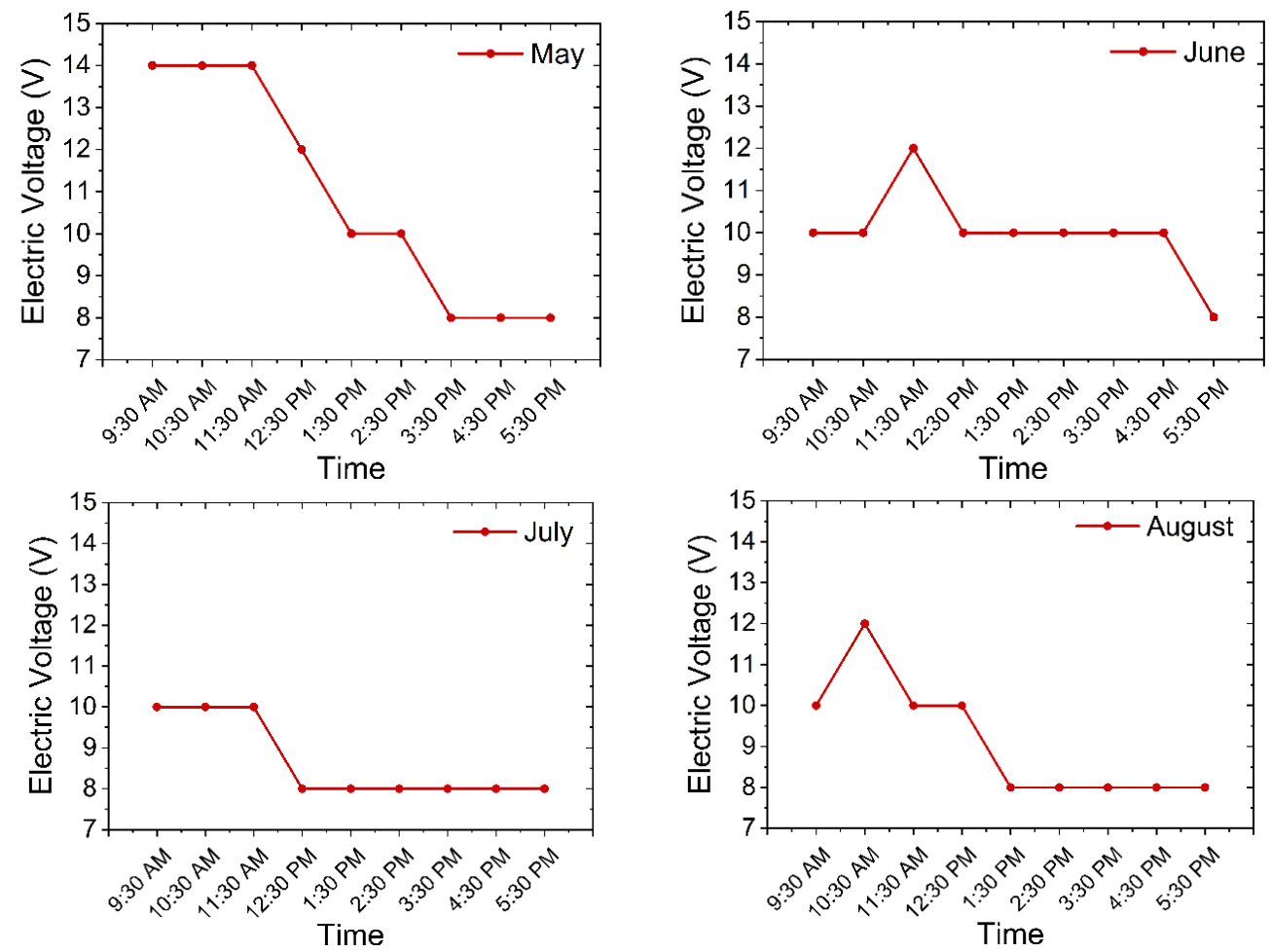

Figure 7. Electric voltage variation with time for TE module

Figure 8 shows the variation of total cooling load and power required by the TEC to run with the time. From the trends for all the months it can be noticed that the maximum power 
required by TEC for maintaining cooling load is falling in the time range of 10.30 am to 11.30 am. When the temperature of the atmosphere is maximum the cooling load is high but for extraction of that much heat from the chamber the power consumed by the TEC is also relatively very high. At 5:30 pm when the atmospheric temperature is very low below $30^{\circ} \mathrm{C}$ the difference between the cooling load and power consumed by TEC is comparatively very low. At some points of time in all four months even for less cooling load the power consumed by TEC is more depending on the performance curves of TEC1-12706 and limitation on the power supply.
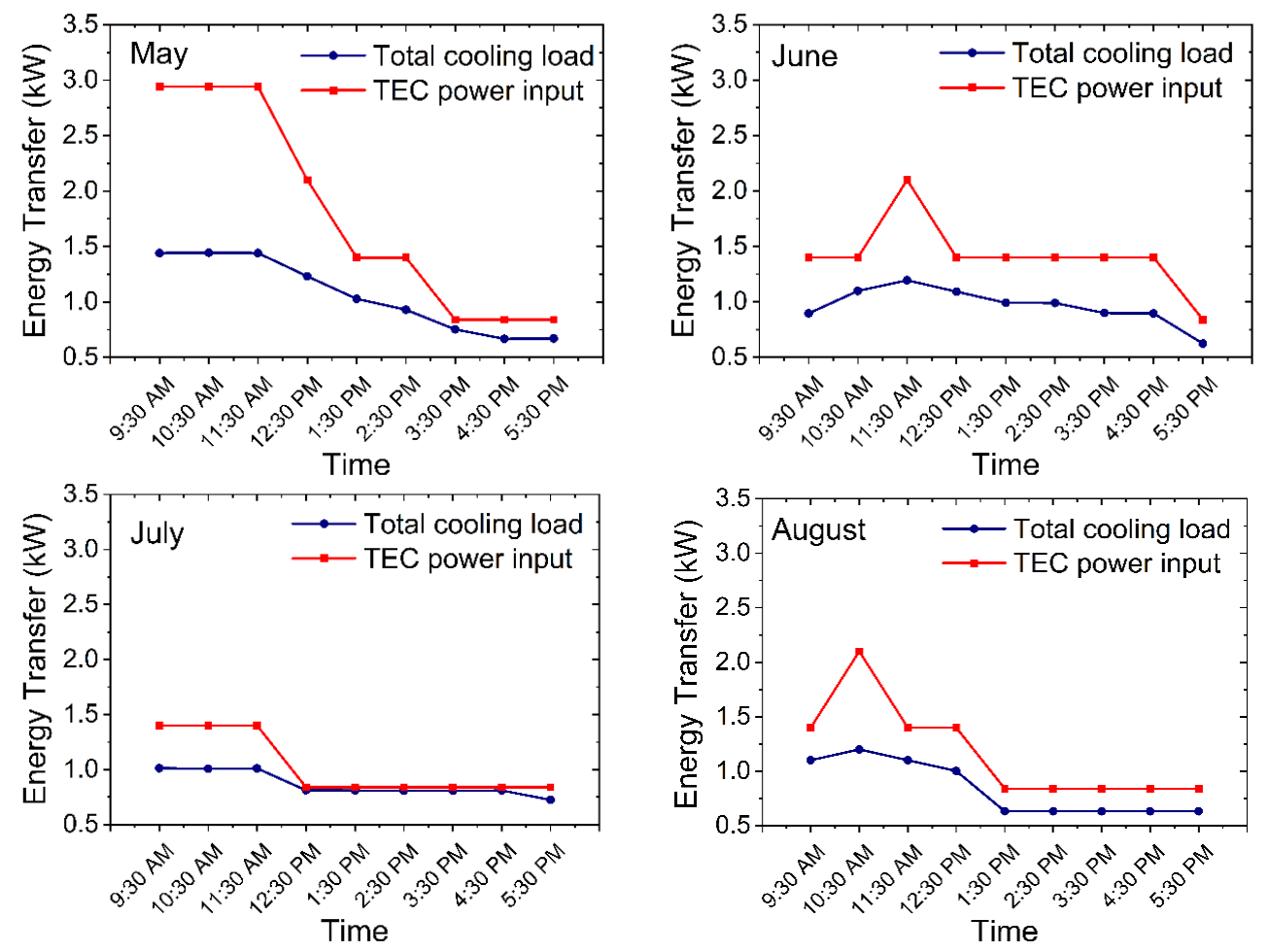

Figure 8. Energy transfer variation with time of power consumed by of TE module and total cooling load

The cooling efficiency of the system is determined in terms of COP (coefficient of performance) as the ratio of total cooling load required and amount of electrical power required to generate it. Figure 9, depicts that the value of COP generally increases as the temperature of the ambient decreases with the time for all the months but for some duration of the time in a day value of COP falls even for less ambient temperature because more electrical power is being supplied than required to maintain the cooling load depending on the 
performance curve of the TEC1-12706. The minimum value of COP is generally recorded for the time duration between $10.30 \mathrm{am}$ to $11.30 \mathrm{am}$. The maximum COP of the system recorded is 0.867 in the month of May and July and minimum COP is 0.47 which also recorded in the month of May.
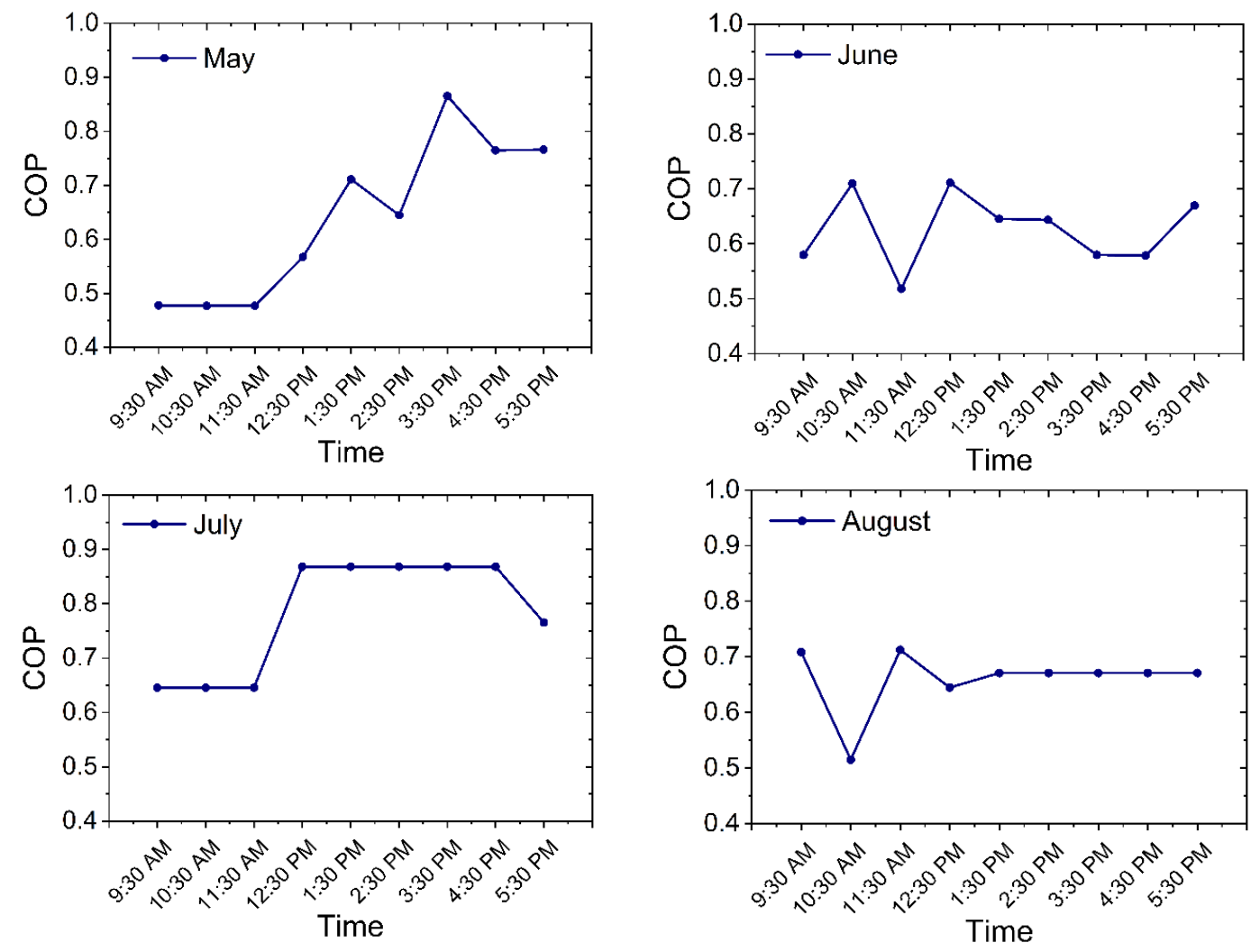

Figure 9. COP variation with time of proposed air-conditioning system

Figure 10, shows the variation of the thermal resistance of the heat sink needed for effective heat dissipation based on cooling load and the power input to the TE module. The value of the required thermal resistance is decreases with the increase in the ambient temperature. The minimum value of thermal resistance required is $0.268{ }^{\circ} \mathrm{C} / \mathrm{W}$ at the ambient temperature of $38^{\circ} \mathrm{C}$. The calculated value of thermal resistance offered by water cooled heat sink used, at maximum value of power input is $0.086^{\circ} \mathrm{C} / \mathrm{W}$. From the plot it is clearly seen that the thermal resistance of water cooled mini-channel used on the hot side is considerably less as per the required thermal resistance therefore the heat sink used if sufficient for effective the working of the TEC. 

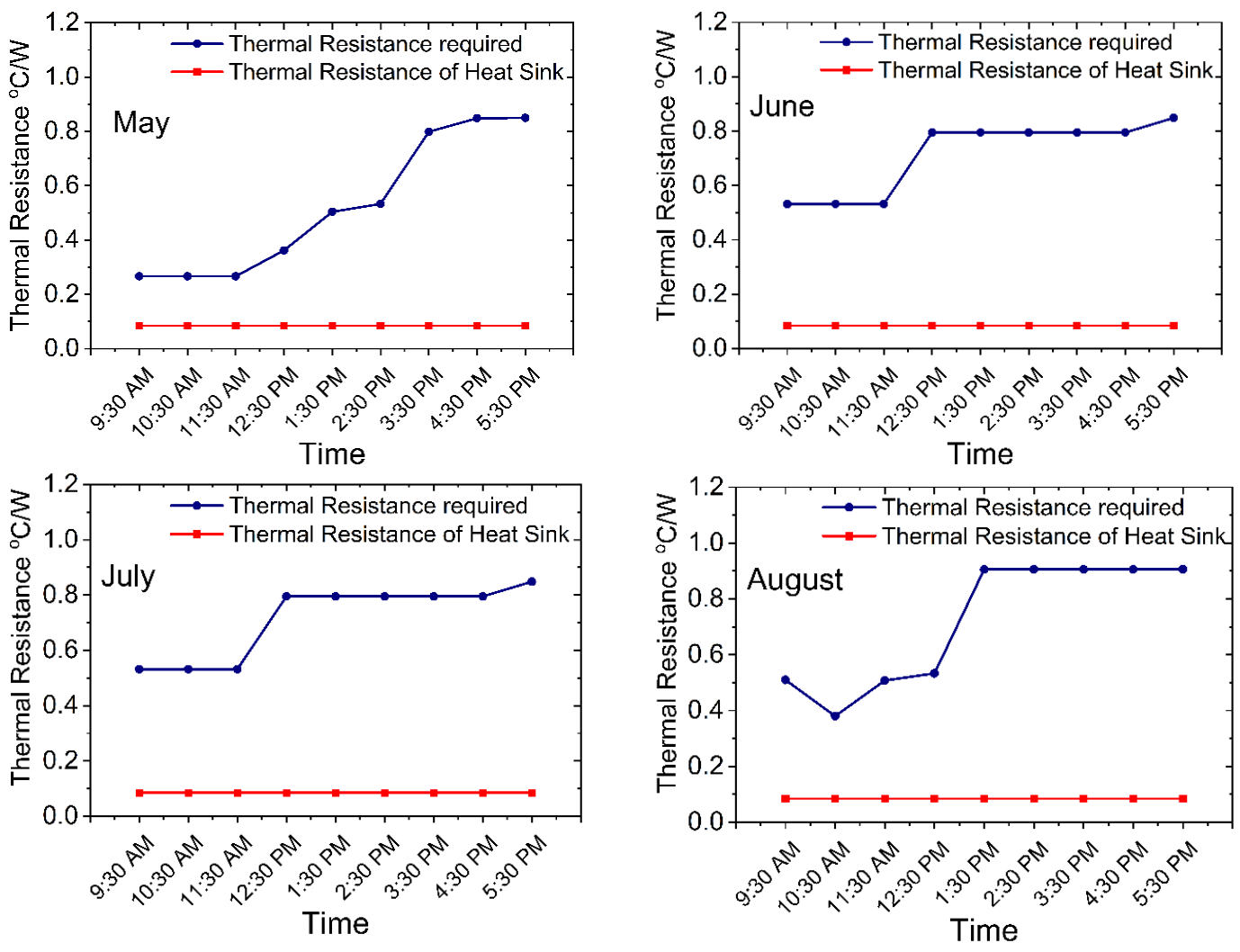

Figure 10. Thermal resistance variation with time of heat sink used and total resistance required by TE module

\section{CONCLUSION}

In the present work an air-conditioning systems is developed and studied. The system is based on amalgam of two different technologies i.e. desiccant dehumidification and TE cooling. The system is studied according to the Indian weather condition in the months of May, June, July and August. The performance of the system is studied and based on the analysis of the results following chief findings are outlined.

- For the higher ambient temperature both cooling load and input power supply to TEC significantly increases and result in lower cooling performance and vice versa. For $18 \%$ drop of the ambient temperature in month of May $81 \%$ increase in the COP is reported.

- For the higher cooling effect performance of the system can be increased by increasing number of TE module for the given input power supply and rregardless of same cooling load, COP of the system reduces with the increase in input power supply to 
TEC.

- The system is successfully able to cool and dehumidify the air with in the thermal comfort zone i.e. $22{ }^{\circ} \mathrm{C}$ and RH $50 \%$ defined by ASHRAE with maximum COP of 0.865 and cooling effect up to $1442.24 \mathrm{~W}$.

- By increasing current intensity and electrical voltage for TEC the thermal resistance need for effective heat dissipation by heat sink also decreases. For $14 \mathrm{~V}$ and $6 \mathrm{~A}$ electrical power supply required thermal resistance is $0.268^{\circ} \mathrm{C} / \mathrm{W}$.

Hence it may be concluding that amalgam of Desiccant Dehumidification and TEC can provide an alternative to VCRS based system.

\section{ACKNOWLEGEMENTS}

This work was supported by the collaborative project scheme (CRS) fund under NATIONAL PROJECT IMPLEMENTATION UNIT (NPIU) (A Unit of MHRD, Govt. of India for Implementation of World Bank Assisted Projects in Technical Education) [CRS Project ID: 1$5736521412]$

\section{REFERENCES}

Building Energy Data Book 2011. US Department of Energy. 2012.

Zhong, B. L., Ling, Z., Guang, C. G., Yong, Q. L. \& Fang, F. M. 2015. Experimental study and performance analysis of a solar thermoelectric air conditioner with hot water supply, Energy and Buildings 86: 619-625.

Berardi, U., La, R. P. \& Almodovar, J. M. 2017. Water-to-air-heat exchanger and indirect evaporative cooling in buildings with green roofs. Energy and Buildings 151: 406-417.

Xi, H., Luo, L. \& Fraisse, G. 2007. Development and applications of solar-based thermoelectric technologies 11(5): 923-936

Luo, D., Wang, R., Yu, W., Sun, Z, \& Meng, X. 2019. Modelling and simulation study of a converging thermoelectric generator for engine waste heat recovery. Appl. Therm. Eng. 153: 837-847. 
Sofrata, H., 1984. Solar Thermoelectric Cooling System. In: S.W. James, B.H. Khoshaim, R. Mallory and A. Meiners, Editors: Solar Buildings. Missouri: Midwest Research Institute $59-76$.

Cheng, T.-C., Cheng, C.-H. \& Huang, Z.-Z. 2011. Development of an energy-saving module via combination of solar cells and thermoelectric coolers for green building applications. Energy 36 (1): 133-140.

Wang, R.Z. \& Dai, Y.J. 2001. Solar thermoelectric refrigerator. Patent No. 01239142, 2001;5, China.

Naphon, P., \& Wiriyasart, S. 2009. Liquid cooling in the mini-rectangular fin heat sink with and without thermoelectric for CPU. Int. Commun. Heat Mass Tran. 36: 166-171.

Choi, H.-S., Yun, S. \& Whang, K-il. 2007. Development of a temperature-controlled carseat system utilizing thermoelectric device. Appl. Therm. Eng. 27: 2841-2849.

Gillott, M., Jiang, L. \& Riffat, S. 2010. An investigation of thermoelectric cooling devices for small-scale space conditioning applications in buildings. Int. J. Energy Res. 34: 776786.

Zuazua-Ros, A., Martín-Gómez, C., Ibañez-Puy, E., Vidaurre-Arbizu, M. \& Gelbstein, Y. 2019. Investigation of the thermoelectric potential for heating, cooling and ventilation in buildings: Characterization options and applications. Renewable Energy 131: 229-239.

Luo, Y., Zhang, L., Bozlar, M., Liu, Z., Guo, H. \& Meggers, F. 2019. Active building envelope systems toward renewable and sustainable energy. Renewable and Sustainable Energy Reviews 104: 470-91.

Tian, M.W., Aldawi, F., Anqi, A.E., Moria, H., Dizaji, H.S. and Wae-hayee, M., 2021. Cost-effective and performance analysis of thermoelectricity as a building cooling system; experimental case study based on a single TEC-12706 commercial module. Case Studies in Thermal Engineering 27: 101366.

Kodama, A., Hirayama, T., Goto, M., Hirose, T. \& Critoph, R.E. 2001. The use of psychometric charts for the optimisation of a thermal swing desiccant wheel. Appl. Therm. 
Eng. 21: 1657-1674.

Steven Brown, j. \& Domanski, P.A. 2014. Review of alternative cooling technologies. Appl. Therm. Eng. 64: (2014) 252-262.

Al-Alili, A. Hwang, Y. \& Radermacher, R. 2015. Performance of a desiccant wheel cycle utilizing new zeolite material: experimental investigation, energy. 81: 137-145.

Ge, T.S., Li, Y., Wang, R.Z. \& Dai, Y.J. 2009. Experimental study on a two-stage rotary desiccant cooling system. International Journal of Refrigeration. 32: 498-508.

Li, H., Dai, Y.J., Köhler, M. \& Wang R.Z. 2013. Simulation and parameter analysis of a two-stage desiccant cooing/heating system driven by solar air collectors. Energy Convers. Manage. 67: 309-317.

Shahzad, M. K., Chaudhary, G. Q., Ali M., Nadeem, Ahmed S., Khalil M.S. \& Tanzeel U. R. 2018. Experimental evaluation of a solid desiccant system integrated with cross flow maisotsenko cycle evaporative cooler. Appl. Therm. Eng. 128: 1476-1487.

Ying, S., Zhang, Y. \& Ge, Z. 2015. Simulation and energy saving analysis of high temperature heat pump coupling to desiccant wheel air conditioning system. Energy 83: $583-596$.

Lee, Y., Park, S. and Kang, S., 2021. Performance analysis of a solid desiccant cooling system for a residential air conditioning system. Applied Thermal Engineering. 182: 116091. 